\title{
TOLERÂNCIA AO ESTRESSE DE CALOR EM GENÓTIPOS DE TRIGO NA FASE DE GERMINAÇÃO $\left(^{(1)}\right.$
}

\author{
ADELIANO CARGNIN $\left({ }^{2}\right)$; MOACIL ALVES DE SOUZA $\left({ }^{3}\right)$; DENISE CUNHA FERNANDES \\ DOS SANTOS DIAS $\left({ }^{3}\right)$; JUAREZ CAMPOLINA MACHADO $\left({ }^{4}\right)$; CARLA GOMES MACHADO $\left({ }^{3}\right)$; \\ VALDINEISOFIATTI $\left({ }^{3}\right)$
}

\begin{abstract}
RESUMO
O objetivo deste trabalho foi verificar o efeito do estresse de calor e avaliar o grau de tolerância de genitores e populações segregantes a esse estresse, na fase de germinação, em condições controladas. Foram utilizadas sementes de oito genitores e oito populações segregantes, colocadas para germinar em papel germitest umedecido sob duas condições de temperatura: $25 / 15{ }^{\circ} \mathrm{C}$ (diurno/noturno) para os tratamentos sem estresse e de $35 / 25{ }^{\circ} \mathrm{C}$ (diurno/noturno) com estresse. O delineamento experimental utilizado foi o de blocos ao acaso com quatro repetições. Para cada repetição foram utilizados dois rolos, um para determinar a massa seca das sementes no terceiro dia após a semeadura e outro para a massa seca das plântulas no décimo dia. Avaliou-se ainda a eficiência do uso do endosperma e calculou-se o índice de estresse. Alta temperatura na fase de germinação das sementes ocasiona redução da massa seca de plântula e eficiência do uso do endosperma. Houve diferença de tolerância ao estresse de calor entre as populações e entre os genitores. Os materiais mais tolerantes ao calor foram: CPAC9662/IVI931009, BR24/Aliança, Aliança e CPAC9662.
\end{abstract}

Palavras-chave: Triticum aestivum L., temperatura, variabilidade genética, germinação da semente.

\section{ABSTRACT \\ TOLERANCE TO HEAT STRESS IN GERMINATING WHEAT GENOTYPES}

This study was carried out to verify the effect of heat stress and the level of parents and segregant populations at the germination phase under controlled conditions. Seeds of eight parents and eight segregant populations were germinated in moistened germitest paper at $25 / 15{ }^{\circ} \mathrm{C}$ (daytime/night) for treatments without stress, and at $35 / 25^{\circ} \mathrm{C}$ (daytime/night) with stress. Randomized block design with four replications was used. For each replication, two germitest paper rolls were used: one for determining the dry matter of the seeds at $3^{\text {rd }}$ day after sowing, and the other one for determining the dry matter of the plantlets at the $10^{\text {th }}$ day after sowing. The efficiency in using the endosperm was evaluated and the stress index calculated. High temperature at seed germination causes reduction in the dry matter of the plantlet and efficiency in using the endosperm. Tolerance varies among parents and populations. The most heat-tolerant genotipes were CPAC9662/IVI931009, BR24/Aliança, Aliança and CPAC9662.

Key words: Triticum aestivum L., temperature, genetic variability, seed germination.

( $\left.{ }^{1}\right)$ Extraído da tese de mestrado apresentada pelo primeiro autor à Universidade Federal de Viçosa (UFV), Viçosa (MG). Recebido para publicação em 13 de abril de 2005 e aceito em 31 de março de 2006.

$\left(^{2}\right)$ Departamento de Genética e Melhoramento, Universidade Federal de Viçosa (UFV), Avenida P. H. Rolfs s/n. ${ }^{\circ}, 36571000$ Viçosa (MG). Autor correspondente. E-mail: adelianoc@hotmail.com

$\left(^{3}\right)$ Departamento de Fitotecnia, Universidade Federal de Viçosa (UFV), Viçosa (MG). E-mail: moacil@ufv.br; dcdias@ufv.br; sufiatti@vicosa.ufv.br; carlagomes@buynet.com.br

( $\left.{ }^{4}\right)$ Departamento de Biologia, Universidade Federal de Lavras (UFLA), Caixa Postal 3037, 37200000 Lavras (MG). E-mail: juarezcmachado@yahoo.com.br 


\section{INTRODUÇÃO}

A principal limitação da cultura do trigo na Região do Brasil-Central é a ocorrência de temperatura muito elevada durante o ciclo dessa cultura. De acordo com Souza e RAMALho (2001), o sucesso da cultura do trigo nessa região depende de vários fatores, dentre os quais a existência de cultivares tolerantes ao calor assume posição de destaque.

Desde o princípio da pesquisa com a cultura do trigo na região do Brasil-Central, por volta da década de 1930, uma das maiores preocupações dos melhoristas tem sido o desenvolvimento de cultivares que possuem tolerância ao calor (THIBAU, 1951; SouZA, 1999).

Em trigo, a existência de variabilidade genética quanto à tolerância ao calor no estádio de plântulas tem sido constatada em alguns trabalhos (Blum e Sinmena, 1994; Alka e Khanna-Chopra, 1995). No entanto, no Brasil, esse tipo de pesquisa é pouco freqüente.

Na fase de germinação da semente, os carboidratos armazenados no endosperma constituem a principal fonte de energia para o processo germinativo e crescimento inicial das plântulas (BUCKERIDGE et al., 2004). Quando essas plântulas são submetidas a altas temperaturas, a eficiência do uso dos carboidratos armazenados é função da tolerância ao calor de cada genótipo, eficiência traduzida pelo menor consumo de carboidratos no processo respiratório, proporcionando maior acúmulo de massa seca na plântula (BLum e SinMENA, 1994).

O desenvolvimento da plântula é totalmente dependente do carbono armazenado no endosperma. A utilização das reservas armazenadas no endosperma para o crescimento da plântula no escuro traduz a eficiência que pode ser obtida com a taxa de ganho em massa na plântula e uma perda em massa seca do endosperma (Blum e Sinmena, 1994).

De acordo com Levite (1982), citado por Blum e Sinmena (1994), a maior perturbação da produtividade da planta sob estresse de calor é atribuída à "fome" de carbono devido à interrupção do processo fotossintético sob estresse de calor e agravada com a perda desse elemento pela elevada taxa de respiração.

Em trabalho realizado por Alka e KHANNACHopra (1995), a resposta de cultivares de trigo às altas temperaturas foi analisada em relação à atividade da amilase e taxa de respiração das sementes na fase de germinação. Esses autores relatam que o crescimento inicial das plântulas é dependente da atividade da $\alpha$-amilase que degrada o amido em maltose e glicose e afirmam que esses açúcares servem como substratos para respiração que favorecem energia para o rápido crescimento do eixo embrionário e a síntese e secreção de $\alpha$-amilase são influenciadas pela temperatura.

Nesse contexto, existem evidências de que a tolerância ao calor da planta adulta está associada com tolerância no estádio de plântula (BLum e SINMENA, 1994). Variação genotípica para tolerância ao calor em trigo, em termos de biomassa, rendimento de grãos e seus componentes foi relacionado ao vigor de crescimento sob estresse de calor, duas a três semanas após a germinação (RAWSON, 1986; SHPILER e BLUM, 1986).

Durante a fase de germinação é possível maior eficiência no processo seletivo com a disponibilidade de técnicas que utilizam poucas sementes. Esse processo permite praticar seleção em condições controladas, já nas primeiras gerações segregantes, com boa correlação ao rendimento de grãos e seus componentes avaliados nos mais diversos ambientes de cultivo.

Alta correlação também foi obtida entre a redução da fotossíntese no estádio de plântula e no florescimento, em decorrência do estresse de calor ocorrido nesses estádios, em 10 cultivares de trigo avaliados (Al-Khatib e PAulsen, 1990).

Dessa forma, a possibilidade de se efetuar a seleção para tolerância ao calor na fase de plântula, em condições controladas é, sem dúvida, uma prática que trará elevada eficiência no processo de seleção e maior progresso do melhoramento da cultura do trigo. Adicionalmente, haverá economia de tempo e de custo nos programas de melhoramento que buscam maior tolerância ao calor para essa cultura.

O objetivo deste trabalho foi verificar o efeito do estresse de calor e avaliar o grau de tolerância de genitores e populações segregantes a esse estresse, na fase de germinação, em condições controladas.

\section{MATERIAL E MÉTODOS}

O experimento foi desenvolvido no Laboratório de Pesquisa de Sementes do Departamento de Fitotecnia, pertencente à Universidade Federal de Viçosa (UFV), em Viçosa (MG).

Foram utilizadas sementes de oito genitores e oito populações segregantes (geração F3) de trigo, oriundas dos seguintes cruzamentos, BH1146/BR24, 
BR24/Aliança, Aliança/EP93541, EP93541/ CPAC9662, CPAC9662/IVI931009, IVI931009/ BRS207, BRS207/Anahuac, Anahuac/BH1146, segundo esquema de dialelo circulante, de acordo com BEARZOTI (1997).

As sementes das oito populações e dos oito genitores foram produzidas durante a estação de inverno na Estação Experimental de Coimbra (MG), pertencente à UFV, seguindo-se as recomendações técnicas para a cultura do trigo (Comissão Centro Brasileira de Pesquisa de Trigo, 2003).

As sementes de cada população segregante e/ ou genitor parental foram colhidas quando atingiram a maturidade fisiológica (plantas com coloração amarelada), a fim de que todos os genótipos atingissem o seu máximo de massa seca e vigor. Depois de colhidas as sementes foram secas ao sol, para permitir o armazenamento seguro, seguindo as recomendações de PESKE et al. (2003).

Em seguida, as sementes foram padronizadas, por classificação em peneiras, de modo que fossem eliminadas aquelas com tamanho muito pequeno decorrente da má formação durante o período de desenvolvimento das sementes. As sementes foram, então, acondicionadas em sacos de papel e colocadas em câmara fria até a realização dos testes de germinação em laboratório.

Antes da semeadura, as sementes passaram por desinfecção externa pela imersão em solução de hipoclorito de sódio a $1 \%$, por um minuto, e posterior lavagem em água destilada por cinco minutos. Em seguida foram semeadas em papel germitest, umedecido com quantidade de água equivalente a 2,5 vezes o peso do papel seco (BRASIL, 1992). Foram confeccionados rolos, mantidos por 72 horas em incubadora B.O.D., a $20{ }^{\circ} \mathrm{C}$, para a embebição das sementes. Após esse período, os rolos foram transferidos para incubadoras B.O.D. reguladas nas seguintes temperaturas: $25 / 15^{\circ} \mathrm{C}$ (diurno/noturno) para os tratamentos sem estresse de calor e de $35 / 25^{\circ} \mathrm{C}$ (diurno/noturno) para os tratamentos com estresse de calor, onde permaneceram por 10 dias (BLUM e SinMENA, 1994).

O delineamento experimental utilizado foi o de blocos ao acaso com quatro repetições. Para cada repetição foram utilizados dois rolos de papel com 50 sementes. Um dos rolos foi utilizado para determinar a massa seca das sementes no terceiro dia e o outro para a massa seca das plântulas. Massa seca das sementes $(\mathrm{mg} /$ semente): realizada utilizando-se 50 sementes que foram pesadas após a secagem em estufa com circulação de ar, a $80^{\circ} \mathrm{C}$, durante 72 horas; Massa seca de plântulas (mg/plântula): foi determinada utilizando-se as plântulas normais obtidas no $100^{\circ}$ dia após a semeadura, retirando-se, com o auxílio de um estilete, o restante da semente que ainda se encontrava aderida à plântula. As plântulas foram colocadas em sacos de papel, permanecendo em estufa com circulação de ar, a $80^{\circ} \mathrm{C}$, por 72 horas. Após esse período, foram pesadas em balança de precisão $(0,01$ g), determinando-se a massa seca de plântula. Foi considerado como plântula, o coleóptilo e a radícula emitidos de cada semente entre o terceiro e o décimo dia após a semeadura.

A eficiência do uso do endosperma foi quantificada pelo acúmulo de massa seca na plântula entre o terceiro e o décimo dia após semeadura, pela expressão de BLUM e SINMENA (1994): $E U E(\%)=\left(\frac{M S_{p}}{M S_{c}}\right) \times 100$, em que: $M S_{p}$ é a massa seca da plântula no décimo dia após a semeadura, e $M S_{C}$ é a massa seca da semente, consumida entre o terceiro e o décimo dia após a semeadura.

Os testes de análises de agrupamento de médias foram feitos utilizando-se o método descrito por Sсотт е Клотт (1974); que possibilita a definição de subconjuntos de genótipos que diferem significativamente entre si. Todas as análises foram feitas com o auxílio do programa computacional Genes (CRUZ, 2001).

Foi feita ainda a quantificação dos efeitos do estresse de calor ocorridos nos tratamentos com estresse em relação aos tratamentos sem estresse por temperatura, obtida pela percentagem de redução (\%) conforme a expressão de WARDLAW et al. (1989): $\% R=\left[1-\left(X_{C} / X_{S}\right)\right] * 100$, em que: $X_{c}$ e $X_{\mathrm{s}}$ são as médias de cada genótipo nos tratamentos com e sem estresse respectivamente. Posteriormente, os genótipos foram classificados em ordem crescente quanto aos seus percentuais de redução (\%R).

\section{RESULTADOS E DISCUSSÃO}

Com valores habituais para esse tipo de ensaio, os coeficientes de variação das duas variáveis nas duas temperaturas de germinação, tanto para os genitores como para as populações segregantes, oscilaram entre 3,27 e 8,43\% (Tabela 1). Os coeficientes de variação obtidos conferem boa precisão ao experimento e confiabilidade, o que tornam praticáveis as inferências sobre os dados analisados (Gomes, 1990). 
Tabela 1. Quadrados médios (QM), valores médios, mínimos e máximos e coeficiente de variação (CV) obtidos das variáveis, massa seca de plântula (MS) e eficiência do uso do endosperma (EUE) de sementes, de oito genitores e oito populações segregantes de trigo, germinadas a temperatura de $25 / 15^{\circ} \mathrm{C}$ e $35 / 25^{\circ} \mathrm{C}$. Viçosa-MG, 2004

\begin{tabular}{|c|c|c|c|c|c|}
\hline Variável & $\mathrm{QM}$ & Média & Mínimo & Máximo & CV $(\%)$ \\
\hline & \multicolumn{5}{|c|}{ Genitores } \\
\hline MS (mg/plântula) a $25^{\circ} \mathrm{C} / 15^{\circ} \mathrm{C}$ & $5,20 * *$ & 14,46 & 11,67 & 16,89 & 6,65 \\
\hline MS (mg/plântula) a $35^{\circ} \mathrm{C} / 25^{\circ} \mathrm{C}$ & $5,14^{* *}$ & 11,95 & 8,92 & 13,93 & 7,82 \\
\hline EUE $(\%)$ a $25^{\circ} \mathrm{C} / 15^{\circ} \mathrm{C}$ & $17,05^{*}$ & 51,78 & 45,03 & 56,45 & 4,19 \\
\hline \multirow[t]{2}{*}{$\operatorname{EUE}(\%)$ a $35^{\circ} \mathrm{C} / 25^{\circ} \mathrm{C}$} & $118,03^{* *}$ & 42,45 & 28,08 & 50,29 & 4,83 \\
\hline & \multicolumn{5}{|c|}{ Populações segregantes } \\
\hline MS (mg/plântula) a $25^{\circ} \mathrm{C} / 15^{\circ} \mathrm{C}$ & $2,30^{*}$ & 12,32 & 9,32 & 14,90 & 6,65 \\
\hline MS (mg/plântula) a $35^{\circ} \mathrm{C} / 25^{\circ} \mathrm{C}$ & $4,01^{* *}$ & 10,88 & 8,05 & 13,36 & 8,43 \\
\hline $\operatorname{EUE}(\%)$ a $25^{\circ} \mathrm{C} / 15^{\circ} \mathrm{C}$ & $5,01 \mathrm{NS}$ & 58,15 & 54,26 & 62,63 & 3,56 \\
\hline $\operatorname{EUE}(\%)$ a $35^{\circ} \mathrm{C} / 25^{\circ} \mathrm{C}$ & $67,98^{* *}$ & 50,73 & 42,55 & 58,86 & 3,27 \\
\hline
\end{tabular}

NS: não significativo; ${ }^{*} \mathrm{e}^{*}$; significativo a $1 \%$ e $5 \%$ de probabilidade respectivamente, pelo teste $\mathrm{F}$.

Os resultados da análise de variância dos caracteres massa seca de plântula e eficiência do uso do endosperma (Tabela 1) evidenciam diferenças significativas entre os genitores, indicando a existência de variabilidade genética tanto na condição favorável $\left(25 / 15^{\circ} \mathrm{C}\right)$, como também, para a condição de estresse por temperatura $\left(35 / 25{ }^{\circ} \mathrm{C}\right)$. Também trabalhando com diferentes temperaturas de germinação, ALKA e KHANNA-CHOPRA (1995) observaram diferentes respostas entre as variedades de trigo para a taxa de crescimento de plântulas, tanto para temperatura de $20^{\circ} \mathrm{C}$ como para a temperatura de 30 ${ }^{\circ} \mathrm{C}$.

Para as populações segregantes, a análise de variância demonstra diferenças significativas entre os tratamentos para as duas condições de germinação somente para o caráter massa seca de plântula, evidenciando que há populações superiores nas duas condições de temperatura para esse caráter. Entretanto, para o caráter eficiência do uso do endosperma, constataram-se diferenças significativas somente para a condição de estresse por temperatura $\left(35 / 25^{\circ} \mathrm{C}\right)$, confirmando a existência de variabilidade genética para este caráter (Blum e SinMENA, 1994).

Sob condições de temperatura favoráveis (25/ $\left.15{ }^{\circ} \mathrm{C}\right)$, a germinação das sementes de todas as populações, observou-se eficiência semelhante na utilização dos carboidratos de reserva do endosperma da semente. Em condições desfavoráveis $\left(35 / 25^{\circ} \mathrm{C}\right)$, houve diferença significativa de comportamento entre as populações, evidenciando que há populações superiores para esse caráter nessa condição de temperatura (estresse).
Constatou-se que as médias dos caracteres avaliados, valores de máximo e mínimo, tanto dos genitores como das populações segregantes tiveram redução, em ambos os caracteres, na temperatura de germinação de $35 / 25^{\circ} \mathrm{C}$ em relação à germinação à temperatura de $25 / 15^{\circ} \mathrm{C}$ (Tabela 1 ). Houve efeito da alta temperatura sobre a utilização das reservas de carboidratos armazenados no endosperma durante o processo de germinação. De acordo com Blum e SINMENA (1994), a utilização das reservas armazenadas no endosperma, medida pelo acúmulo de matéria seca das plântulas no escuro, é maior aos $25 / 15^{\circ} \mathrm{C}$ do que aos $35 / 25^{\circ} \mathrm{C}$ e variável com as diferentes cultivares. Segundo AlKa e Khanna-Chopra (1995), a inabilidade de crescimento do embrião à alta temperatura, pode ser decorrente da inibição da síntese de proteínas além da redução na atividade das enzimas como ATPase, $\alpha$-amilase, glutamina sintase e fumarase.

Para os genitores, a média do caráter massa seca de plântula passou de $14,46 \mathrm{mg} /$ plântula, sob temperatura de $25 / 15^{\circ} \mathrm{C}$, para $11,95 \mathrm{mg}$ / plântula a $35 / 25{ }^{\circ} \mathrm{C}$, ocorrendo redução de $17,36 \%$. Semelhante redução $(18,02 \%)$ foi encontrada para a eficácia do uso do endosperma que passou de $51,78 \%$ para $42,45 \%$ de eficiência de uso das reservas. Essas reduções podem ser evidências do aumento da taxa de respiração com perdas de carboidratos armazenados no endosperma durante o processo de germinação.

Da mesma forma, verifica-se nas populações segregantes comportamento semelhante em termos de redução na média geral, apesar de proporcionar médias pouco inferiores para o caráter massa seca de plântula e superiores para a eficiência do uso do 
endosperma. O fato de que as médias da eficiência do uso do endosperma, em ambas as condições de temperatura de germinação, foram maiores nas populações segregantes em relação aos genitores, pode ser decorrente das populações segregantes terem maior freqüência de locos com alelos favoráveis pela complementação gênica de dois pais (Souza e RAMALHO, 2001).

Esses resultados são semelhantes aos verificados por Blum e SinMENA (1994) em trabalho realizado com cultivares de trigo. De acordo com esses autores, o estresse provocado por altas temperaturas reduz a eficiência da conversão das reservas do endosperma em tecidos da plântula, devido à grande perda de carboidratos pelo processo de respiração. Para Melo et al. (2004), o aumento da temperatura resulta em altas taxas de respiração e plântulas que não são capazes de suprir as perdas de carbono por altas taxas de respiração acabam morrendo. Segundo AlKa e Khanna-Chopra (1995), existe diferença na atividade da amilase à temperatura de $30{ }^{\circ} \mathrm{C}$ em sementes de cultivares de trigo e relatam que, a tolerância à alta temperatura no crescimento de plântula está relacionada à atividade da amilase.
Não foi possível a formação de grupos de populações superiores quanto aos caracteres massa seca de plântula e eficiência do uso do endosperma à temperatura de germinação de $25 / 15{ }^{\circ} \mathrm{C}$ pelo teste de agrupamento de médias (Tabela 2), evidenciando que todas as populações possuem comportamento semelhante. Por outro lado, essas mesmas populações quando submetidas à temperatura de germinação de $35 / 25{ }^{\circ} \mathrm{C}$ (condição de estresse), proporcionam a formação de dois grupos quanto ao caráter massa seca de plântula; por esse nota-se a superioridade de algumas populações, confirmando a existência de variabilidade genética para tolerância ao calor na fase de germinação para esse caráter.

Da mesma forma, para o caráter eficiência do uso do endosperma (EUE) também ocorreu a formação de grupos à temperatura de germinação de $35 / 25^{\circ} \mathrm{C}$ (condição de estresse). Nesse caso, foi possível constituir quatro grupos de populações que diferem entre si para esse caráter, comprovando a existência de variabilidade entre as populações, principalmente em relação à massa seca de plântula. Por essas evidências constata-se a eficácia do uso do endosperma, sendo um bom indicador de tolerância ao calor na fase de germinação.

Tabela 2. Médias de massa seca (MS) e eficiência do uso do endosperma (EUE) de sementes de oito populações segregantes e oito genitores de trigo, germinadas a temperatura de $25 / 15^{\circ} \mathrm{C}$ e $35 / 25^{\circ} \mathrm{C}$. Viçosa, $\mathrm{MG}, 2004$

\begin{tabular}{|c|c|c|c|c|}
\hline \multirow{2}{*}{ Germoplasma } & \multicolumn{2}{|c|}{ MS (mg/plântula) } & \multicolumn{2}{|c|}{ EUE $(\%)$} \\
\hline & $25 / 15^{\circ} \mathrm{C}$ & $35 / 25^{\circ} \mathrm{C}$ & $25 / 15^{\circ} \mathrm{C}$ & $35 / 25^{\circ} \mathrm{C}$ \\
\hline \multicolumn{5}{|l|}{ Populações segregantes } \\
\hline 1-BH 1146/BR 24 & 12,5 a & 12,3 a & 55,9 a & $47,9 \mathrm{c}$ \\
\hline 2-BR 24/Aliança & $12,1 \mathrm{a}$ & $11,7 \mathrm{a}$ & 59,3 a & 55,3 a \\
\hline 3-Aliança /EP 93541 & $11,2 \mathrm{a}$ & $10,5 \mathrm{~b}$ & 57,7 a & $53,2 \mathrm{~b}$ \\
\hline 4-ЕР 93541/СРАС 9662 & $12,6 \mathrm{a}$ & $10,0 \mathrm{~b}$ & $59,4 \mathrm{a}$ & $52,5 \mathrm{~b}$ \\
\hline 5-CPAC 9662/IVI 931009 & $12,8 \mathrm{a}$ & $11,7 \mathrm{a}$ & $58,4 \mathrm{a}$ & 55,8 a \\
\hline 6-IVI 931009/BRS 207 & 13,7 a & $11,1 \mathrm{a}$ & 58,3 a & $44,6 \mathrm{~d}$ \\
\hline 7-BRS 207 / Anahuac & $11,7 \mathrm{a}$ & $9,2 \mathrm{~b}$ & 58,8 a & $46,6 \mathrm{~d}$ \\
\hline 8-Anahuac/BH 1146 & $12,1 \mathrm{a}$ & $10,5 \mathrm{~b}$ & 57,6 a & $50,0 \mathrm{c}$ \\
\hline \multicolumn{5}{|l|}{ Genitor } \\
\hline 1-BH 1146 & 15,8 a & 13,0 a & 53,6 a & 45,6 a \\
\hline 2-BR 24 & $12,9 \mathrm{~b}$ & 12,6 a & 53,8 a & 45,9 a \\
\hline 3-Aliança & $13,3 \mathrm{~b}$ & 13,0 a & $48,1 \mathrm{a}$ & $43,3 \mathrm{a}$ \\
\hline 4-EP 93541 & $14,1 \mathrm{~b}$ & $12,0 \mathrm{a}$ & 51,9 a & $44,6 \mathrm{a}$ \\
\hline 5-СРАС 9662 & $13,7 \mathrm{~b}$ & 11,5 a & $51,2 \mathrm{a}$ & $45,4 \mathrm{a}$ \\
\hline 6-IVI 931009 & $14,7 \mathrm{a}$ & 11,7 a & 49,5 a & $39,2 \mathrm{~b}$ \\
\hline 7-BRS 207 & 15,4 a & $9,5 \mathrm{~b}$ & $53,1 \mathrm{a}$ & $30,2 \mathrm{c}$ \\
\hline 8-Anahuac & $15,8 \mathrm{a}$ & $12,5 \mathrm{a}$ & $53,1 \mathrm{a}$ & $45,7 \mathrm{a}$ \\
\hline
\end{tabular}

Médias seguidas pela mesma letra na coluna não diferem estatisticamente entre si pelo teste de agrupamento de médias de Scott e Knott a $5 \%$ de probabilidade. 
Entre as populações segregantes avaliadas destacaram-se BR24/Aliança e CPAC9662/IVI931009, que foram superiores em relação às demais para os dois caracteres nas duas condições de temperatura, evidenciando serem fontes de variabilidade para tolerância ao calor na fase de germinação.

Mesmo encontrando-se no grupo de genótipos superiores em relação à massa seca de plântula na temperatura de $35 / 25^{\circ} \mathrm{C}$ (condição de estresse), a população IVI931009/BRS207 apresentou forte redução deste caráter. A eficiência do uso das reservas do endosperma também decresceu nessa temperatura em relação às outras populações, indicando elevada taxa de respiração das reservas do endosperma quando submetidas a altas temperaturas.

Do mesmo modo, para os genitores (Tabela 2), o comportamento foi semelhante ao das populações segregantes, no entanto, foram formados dois grupos de genótipos para o caráter massa seca de plântula à temperatura de $25 / 15^{\circ} \mathrm{C}$ e $35 / 25^{\circ} \mathrm{C}$. Nesse caso, destacou-se negativamente a cultivar BRS207 com a menor massa seca de plântula na condição de estresse demonstrando sensibilidade deste genótipo à alta temperatura. De fato, nessa cultivar ainda notou-se a menor eficiência do uso de reservas do endosperma na temperatura 35/25 ${ }^{\circ} \mathrm{C}$. Este fato pode estar relacionado à elevada atividade da enzima $\alpha$-amilase em altas temperaturas da cultivar BRS207, a qual possui alta suscetibilidade à germinação na espiga, chegando a desencadear o processo de germinação somente pelo efeito da alta temperatura.

Os índices de estresse de calor, determinados pela percentagem de redução (\%R) da massa seca de plântulas e eficiência do uso do endosperma das populações segregantes e dos genitores à temperatura de $35 / 25^{\circ} \mathrm{C}$ em relação a $25 / 15{ }^{\circ} \mathrm{C}$, estão relacionados na tabela 3 . Contataram-se diferenças de tolerância ao estresse de calor entre as populações e entre os genitores, evidenciando a existência de variabilidade genética e, a possibilidade de seleção para tolerância ao calor na fase de germinação.

Verifica-se que o desempenho entre as populações e os genitores é muito semelhante em seus comportamentos, tanto para o agrupamento de médias dos caracteres avaliados como para os índices de redução $(\% R)$, nas duas temperaturas de germinação; esse exemplo pode ser demonstrado pelo fato da correlação classificatória de Spearman ser alta e positiva $(r=0,76, p \leq 0,05)$, para o caráter eficiência do uso do endosperma entre os índices de estresse de calor das populações segregantes e dos genitores.

Tabela 3. Percentuais de redução (R) da massa seca (MS) e eficiência do uso do endosperma (EUE) e classificação de sementes (Cls.), de oito populações segregantes e oito genitores de trigo germinadas a temperatura de $35 / 25^{\circ} \mathrm{C}$ em relação a $25 / 15^{\circ} \mathrm{C}$. Viçosa, MG, 2004

\begin{tabular}{lcccc}
\hline \multirow{2}{*}{ Germoplasma } & \multicolumn{2}{c}{ MS (mg/plântula) } & & EUE (\%) \\
\cline { 2 - 3 } População segregante & $\mathrm{R}(\%)$ & $\mathrm{Cls}$ & & $\mathrm{Cls}$ \\
1-BH 1146/BR 24 & 1,7 & 1 & 14,3 & 6 \\
2-BR 24/ Aliança & 3,1 & 2 & 6,7 & 2 \\
3-Aliança/EP 93541 & 5,8 & 3 & 7,7 & 3 \\
4-EP 93541/CPAC 9662 & 20,0 & 7 & 11,5 & 4 \\
5-CPAC 9662/IVI 931009 & 8,5 & 4 & 4,5 & 1 \\
6-IVI 931009/BRS 207 & 19,2 & 6 & 23,5 & 7 \\
7-BRS 207/Anahuac & 21,1 & 8 & 20,6 & 5 \\
8-Anahuac/BH 1146 & 13,3 & 5 & 13,2 & \\
Genitor & & & & 5 \\
1-BH 1146 & 17,9 & 5 & 15,2 & 1 \\
2-BR 24 & 2,0 & 1 & 14,7 & 4 \\
3-Aliança & 2,3 & 2 & 10,1 & 2 \\
4-EP 93541 & 15,4 & 3 & 14,1 & 7 \\
5-CPAC 9662 & 16,0 & 4 & 11,4 & 3 \\
6-IVI 931009 & 20,6 & 20,7 & 3 \\
7-BRS 207 & 38,3 & 8 & 43,2 & \\
8-Anahuac & 20,7 & 7 & 13,8 & \\
\hline
\end{tabular}


Na interpretação dos índices de estresse, preferiu-se dar ênfase às eficiências do uso das reservas do endosperma obtidas em condições de temperatura elevada (condição de estresse por temperatura), porque a utilização das reservas do endosperma para crescimento da plântula no escuro traduz a eficiência que pode ser obtida com a taxa de ganho em massa seca na plântula e perda em massa seca do endosperma (Blum e Sinmena, 1994).

Desse modo, dentre as populações segregantes com maior eficiência do uso das reservas do endosperma, principalmente a alta temperatura, e com baixo valor de índice de estresse de calor, podem ser destacadas: CPAC9662/IVI931009 e BR24/ Aliança. Entre os genitores podem ser enfatizados: Aliança e CPAC9662, com boa tolerância ao calor na fase de germinação.

\section{CONCLUSÕES}

1. A alta temperatura na fase de germinação ocasiona redução da massa seca de plântula e da eficiência de uso do endosperma.

2. Há tolerância ao estresse de calor entre as populações e entre os genitores na fase de germinação.

3. Os materiais mais tolerantes ao calor na fase de germinação são as populações segregantes BR24/ Aliança e CPAC9662/IVI931009, e os genitores Aliança e CPAC9662.

\section{AGRADECIMENTOS}

O presente trabalho foi realizado com o apoio do Conselho Nacional de Desenvolvimento Científico e Tecnológico-CNPq e da Universidade Federal de Viçosa-UFV, Viçosa-MG.

\section{REFERÊNCIAS}

ALKA, S.; KHANNA-CHOPRA, R. Influence of temperature on germination and seedling growth and its relationship with amylase activity and respiration in wheat varieties differing in temperature tolerance. Indian Journal of Experimental Biology, New Delhi, v.33, p.775-779, 1995.

AL-KHATIB, K.; PAULSEN, G. M. Photosynthesis and productivity during high-temperature stress of wheat genotypes from major world regions. Crop Science, Madison, v.30, p.1127-1132, 1990.

BEARZOTI, E. Simulação de seleção recorrente assistida por marcadores moleculares em espécies autógamas. 1997. 230p. Tese (Doutorado) - Escola Superior de Agricultura Luiz de Queiroz, Piracicaba.
BLUM, A.; SINMENA, B. Wheat seed endosperm utilization under heat stress and its relation to thermotolerance in the autotrophic plant. Field Crops Research, Amsterdam, v.37, n.3, p.185 191, 1994.

BRASIL. Ministério da Agricultura e da Reforma Agrária. Regras para análise de sementes. Brasília: SNDA/DNDV/ CLAV, 1992. 365p.

BRUCKERIDGE, M.S.; SANTOS, H. P.; TINÉ, M. A. S.; AIDAR, M. P. M. Mobilização de reservas. In: FERREIRA, A. G.; BORGHETTI, F. (Ed.). Germinação: do básico ao aplicado. Porto Alegre: Artimed, 2004. p.163-185.

COMISSÃO CENTRO BRASILEIRA DE PESQUISA DE TRIGO. Indicações técnicas para a cultura de trigo na região do BrasilCentral - Safra 2003/2004. Passo Fundo: Embrapa Transferência de Tecnologia - Escritório de Negócios do Triângulo Mineiro, 2003. 109p.

CRUZ, C. D. Programa Genes: versão Windows; aplicativo computacional em genética e estatística. Viçosa: UFV, 2001. 648p.

GOMES, F. P. Coeficiente de variação. In: Escola Superior de Agricultura "Luiz de Queiroz". Curso de estatística experimental. Piracicaba, 1990. 7p.

MELO, F. P. L.; NETO, A. V. A.; SIMABUKURO, E. A.; TABARELLI, M. Recrutamento e estabelecimento de plântulas. In: FERREIRA, A. G.; BORGHETTI, F. (Ed.). Germinação: do básico ao aplicado. Porto Alegre: Artimed, 2004. p.237-250.

PESKE, S. T.; ROSENTHAL, M. A.; ROTA, G. R. M. Sementes: fundamentos científicos e tecnológicos. 1.ed. Pelotas, 2003. 415p.

RAWSON, H. M. High-temperature tolerant wheat: a description of variation and a search for some limitations to productivity. Field Crops Research, Amsterdam, v.14, p.197212, 1986

SCOTT, A. J.; KNOTT, M. A. Cluster analysis methods for grouping means in the analysis of variance. Biometrics, Washington, v.30, n.3, p.507-512, 1974.

SHPILER, L.; BLUM, A. Differential reactions of wheat cultivars to hot environment. Euphytica, Dordrecht, v.35, n.2, p.483492,1986

SOUZA, M. A. Controle genético e resposta ao estresse de calor de cultivares de trigo. 1999. 152p. Tese (Doutorado) Universidade Federal de Lavras, Lavras.

SOUZA, M. A.; RAMALHO, M. A. P. Controle genético e tolerância ao estresse de calor em populações híbridas e em cultivares de trigo. Pesquisa Agropecuária Brasileira, Brasília, v.36, n.10, p.1245-1253, 2001.

THIBAU, C. E. A cultura do trigo e sua importância para Minas Gerais. Belo Horizonte, Departamento de ProduçãoVegetal/ Secretaria da Agricultura, Indústria e Comércio e Trabalho, 1951. 39p.

WARDLAW, I. F.; DAWSON, I. A.; MUNIBI, P. The tolerance of wheat to high temperatures during reproductive growth: II. Grain development. Australian Journal of Agricultural Research, Collingwood, v.40, n.1, p.15-24, 1989. 